\title{
Article
}

\section{Topical delivery of tetrahydrocurcumin lipid nanoparticles effectively inhibits skin inflammation: in vitro and in vivo study}

Kakkar, Vandita, Kaur, Indu Pal, Kaur, Amrit Pal, Saini, Komal and Singh, Kamalinder

Available at http://clok.uclan.ac.uk/23445/

Kakkar, Vandita, Kaur, Indu Pal, Kaur, Amrit Pal, Saini, Komal and Singh, Kamalinder ORCID: 0000-0001-7325-0711 (2018) Topical delivery of tetrahydrocurcumin lipid nanoparticles effectively inhibits skin inflammation: in vitro and in vivo study. Drug Development and Industrial Pharmacy, 44 (10). pp. 1701-1712. ISSN 0363-9045

It is advisable to refer to the publisher's version if you intend to cite from the work. http://dx.doi.org/10.1080/03639045.2018.1492607

For more information about UCLan's research in this area go to http://www.uclan.ac.uk/researchgroups/ and search for <name of research Group>.

For information about Research generally at UCLan please go to http://www.uclan.ac.uk/research/

All outputs in CLoK are protected by Intellectual Property Rights law, including Copyright law. Copyright, IPR and Moral Rights for the works on this site are retained by the individual authors and/or other copyright owners. Terms and conditions for use of this material are defined in the policies page. 


\section{Topical Delivery of Tetrahydrocurcumin Lipid Nanoparticles Effectively Inhibits Skin Inflammation: In Vitro in Vivo Study}

Vandita Kakkar ${ }^{1 *}$, Indu Pal Kaur ${ }^{1}$, Amrit Pal Kaur ${ }^{1}$, Komal Saini ${ }^{1}$, Kamalinder K Singh ${ }^{2}$

${ }^{1}$ Department of Pharmaceutics, University Institute of Pharmaceutical Sciences, Panjab University, Chandigarh, 160014, India.

${ }^{2}$ School of Pharmacy and Biomedical Sciences, Faculty of Clinical and Biomedical Sciences, University of Central Lancashire, United Kingdom, PR1 2HE.

Vandita Kakkar* (Assistant Professor, University Institute of Pharmaceutical Sciences, vanditakakkar@yahoo.co.in)

Indu Pal Kaur (Professor, University Institute of Pharmaceutical Sciences, indupalkaur@yahoo.com)

Amrit Pal Kaur (Research Scholar, University Institute of Pharmaceutical Sciences, akaur0896@gmail.com)

Komal Saini (Research Scholar, University Institute of Pharmaceutical Sciences, komalsainiks@gmail.com)

Kamalinder K Singh (Professor, School of Pharmacy and Biomedical Sciences, Faculty of Clinical and Biomedical Sciences University of Central Lancashire, Preston, Lancashire, UK PR1 2HE, KSingh1@uclan.ac.uk)

\footnotetext{
*Corresponding Author

Dr. Vandita Kakkar

Assistant Professor, Department of Pharmaceutics, University Institute of Pharmaceutical Sciences, Panjab University, Chandigarh, 160014, India.
} 


\begin{abstract}
Tetrahydrocurcumin (THC) also referred to as "white curcumin", is a stable colourless hydrogenated product of curcumin with superior antioxidant and anti-inflammatory properties. Present study is an attempt to elevate the topical bioavailability of THC, post incorporation into a nano-carrier system with its final dosage as a hydrogel. Lipid nanoparticles of THC (THC-SLNs) prepared by microemulsification technique were ellipsoidal in shape (revealed in TEM) with a mean particle size of $96.6 \mathrm{~nm}$ and zeta potential of $-22 \mathrm{mV}$. Total drug content and entrapment efficiency of THC-SLNs was $94.51 \% \pm 2.15 \%$ and $69.56 \% \pm 1.35 \%$, respectively. DSC and XRay diffraction studies confirmed the formation of THC-SLNs. In vitro drug release studies showed the drug release from THC-SLNs gel to follow Higuchi's equation revealing a Fickian diffusion. Ex-vivo permeation studies indicated a 17 times (approximately) higher skin permeation of THC-SLNs gel as compared with the free THC gel. Skin irritation, occlusion and stability studies indicated the formulation to be non-irritating, and stable with a desired occlusivity. Pharmacodynamic evaluation in an excision wound mice model clearly revealed the enhanced anti-inflammatory activity of THC-SLNs gel and confirmed using biochemical and histopathological studies. It is noteworthy to report here that THC-SLNs gel showed significantly better ( $\mathrm{p} \leq 0.001)$ activity than free THC in gel. As inflammation is innate to all the skin disorders, the developed product opens up new therapeutic avenues for several skin diseases. To best of our knowledge, this is the first paper elaborating the therapeutic usefulness of white curcumin loaded lipidic nanoparticles for skin inflammation.
\end{abstract}

Keywords: Tetrahydrocurcumin; skin inflammation; solid lipid nanoparticles (SLNs); bioavailability; histopathology; occlusion; ex-vivo permeation 


\section{Introduction}

Curcumin, a yellow coloured polyphenolic compound derived from the rhizome of the herb Curcuma longa L, has been characterized as an excellent molecule among many naturally occurring compounds, for treatment of several skin inflammatory conditions like atopic dermatitis $^{1-3}$. It alleviates the skin conditions by mode of antioxidant and anti-inflammatory actions in addition to wound repairing capabilities ${ }^{4-6}$. However, inspite of its proven efficacy and safety, it has not yet been approved as a therapeutic agent and till date no commercialisation is in pipeline. Major limitations to the latter are its low bioavailability assigned to it poor aqueous solubility (11 $\mathrm{ng} / \mathrm{mL}$ ) especially at acidic and physiological $\mathrm{pH}$, higher $\log \mathrm{P}$ value of 3.29 , and instability at physiological $\mathrm{pH}$ (7.4) and in the presence of light ${ }^{7}$. In this regard, several nanotechnology based drug delivery systems are being developed. These include polymeric nanoparticles ${ }^{8}$, solid lipid nanoparticles $^{9-11}$, liposomes ${ }^{12}$, and microemulsions ${ }^{13,14}$. However, a major problem associated with the topical application of curcumin is the yellow stain left on the skin post application.

Tetrahydrocurcumin (THC), a metabolite of curcumin is prophesied beneficial for local treatments in the gut ${ }^{15-17}$. It is an excellent antioxidant molecule which possesses superior stability at physiological $\mathrm{pH}(7.4)^{18}$ and in plasma, in addition to being colourless. Moreover, THC is reported to possess an anti-inflammatory activity better than curcumin ${ }^{18}$. THC is however an underexplored molecule for its application in topical disorders though a few reports do indicate its use in cosmetic preparations as a depigmenting agent ${ }^{19}$. Due to its poor aqueous solubility $(0.0056 \mathrm{mg} / \mathrm{mL})$ and a $\log \mathrm{P}$ value of 2.98 , THC could be expected to be a poor skin permeant ${ }^{20,21}$.

Nano-couturing of phytochemicals, has been evidenced to result in bioavailable formulations as a result of improved solubility and stability. Conventional topical treatment using ointments or creams requires frequent application and has shown variable patient responses which results in 
reduced patient compliance. Nanoparticles based drug delivery systems (e.g., liposomes, nano and microemulsions and lipid nanoparticles) have received particular attention for their ability to improve penetration across stratum corneum and for their specific targeting properties ${ }^{22}$.

Drug loaded lipid based nanoparticles in form of a dispersion or post incorporation into a hydrogel, ointment or a cream base have shown advantages like increased bioavailability, physical stability, protection of incorporated thermolabile drugs from degradation and controlled release $\mathrm{e}^{23-25}$.

Present study is an attempt to improve the topical bioavailability of THC, post incorporation into a nano-carrier system(s) with its final dosage as a hydrogel. SLNs, were prepared using a spontaneous, feasible and lab scalable microemulsification technique. THC-SLNs dispersion was evaluated for particle size, polydispersity index (PI), zeta potential, total drug content, entrapment efficiency and TEM. DSC and X-ray diffraction studies were performed to confirm the formation of THC-SLNs. In vitro drug release via SLNs was carried out using dialysis membrane. Further, THC-SLNs hydrogel was evaluated for $\mathrm{pH}$, rheological characteristics, and occlusivity measurements were also carried out. These were followed by skin irritancy (OECD 404) and exvivo permeation studies in animals. Stability studies were performed on the THC-SLNs and its hydrogel in accordance to ICH guidelines Q1A (R2). Finally, the proof of concept studies in an excision wound mice model of inflammation was performed. As inflammation is innate to most of the skin disorders, it was proposed to evaluate its efficacy in an excision wound mice model, wherein the role of oxidative stress in addition to inflammation has been indicated. Post topical application, efficacy of THC-SLNs gel in terms of antioxidant balance and anti-inflammatory activity was determined. Though ample research on nanotechnological intervention on curcumin has been reported and published by us and other scientists working in this area, however, white curcumin has remained as an unexplored molecule. To the best of our knowledge this is the first 
paper elaborating the therapeutic usefulness of white curcumin for skin inflammation with superior properties of providing a cosmetic elegance to the product owing to its colorless and non-staining nature in addition to being a better anti-oxidant and an anti-inflammatory agent.

\section{Material and methods}

\section{Materials}

Tetrahydrocurcumin was a generous gift sample from Sanat Pharmaceuticals Ltd. (New Delhi, India). Carbopol ${ }^{\circledR} 934$, disodium hydrogen phosphate, sodium carbonate, sodium dihydrogen phosphate and tween 80 were obtained from Central Drug House (P) Ltd. (New Delhi, India). Compritol $^{\circledR}$ 888ATO was obtained as gift sample from Panacea Biotec (Lalru, Punjab). Chloroform and diethyl ether were purchased from Sisco Research Laboratories (Mumbai, India). Ethylene diamine tetra acetic acid and triethanolamine were supplied by SD Fine Chemicals (Mumbai, India). Formalin and hydrochloric acid were obtained by Qualigens Fine Chemicals (Mumbai, India). Ellman reagent was purchased from Himedia Laboratories Ltd. (Mumbai, India). Methanol and polyethylene glycol were obtained from Fisher Scientific (Mumbai, India). Ethanol was obtained from Changshu Yanguan Chemicals (China). Phospholipon G was procured as a gift sample from Gattefosse SAS, France.

\section{Preparation of THC-SLNS}

THC loaded SLNs were prepared by microemulsification method ${ }^{26}$. Briefly, tween $80(30 \%)$, phosphatydylcholine (PC) (2\%) and water were placed together in a beaker and heated to the lipid melting temperature. Compritol ${ }^{\circledR} 888$ ATO $(7.27 \%)$ was also melted at $82-85^{\circ} \mathrm{C}$ separately. THC $(0.2 \%)$ was added to the aqueous phase, following which the hot aqueous emulsifier mix, was dropped at once into the lipid melt, under magnetic stirring to obtain a clear microemulsion. The hot microemulsion thus formed, was transferred into an equivalent amount of cold water $\left(2^{\circ} \mathrm{C}\right)$ 
under continuous mechanical stirring $(5000 \mathrm{rpm})$ for 1.5 hour. In the aqueous medium, SLNs were formed by crystallization of the lipid droplets present in the microemulsion.

\section{Incorporation of THC-SLNs into a hydrogel system}

For improving the acceptability and patient compliance, prepared THC-SLNs were incorporated into a hydrogel base. Latter is purported to improve the spreadability of the prepared SLNs dispersion on topical application. Carbopol ${ }^{\circledR} 934(500 \mathrm{mg})$ was dispersed in $25 \mathrm{~mL}$ of water and kept overnight for swelling. Triethanolamine $(0.75 \mathrm{~g})$ was added to this mixture with continuous stirring, to effect gelling of $\mathrm{Carbopol}^{\circledR}$ 934. Stirring was continued until a translucent gel was formed. Then, $25 \mathrm{~mL}$ of THC-SLNs dispersion was added to the prepared gel and mixed slowly to obtain a homogenous mixture containing $1 \% \mathrm{w} / \mathrm{v}$ of Carbopol ${ }^{\circledR} 934$ and $0.2 \% \mathrm{w} / \mathrm{w}$ concentration of THC. Free drug gel comprising of Carbopol ${ }^{\circledR} 934(1 \%$ w/v) was prepared by incorporation of similar THC concentration $(0.2 \% \mathrm{w} / \mathrm{w})$ as contained in THC-SLNs. We wish to highlight here that as THC is not soluble in water, the addition of the drug into the gel base, though produced a nonhomogeneous mixture, in comparison to gel of THC-SLNs, however, it was subjected to homogenization to ensure a uniform distribution of drug in the gel.

\section{Characterization of THC-SLNs and THC-SLNs loaded hydrogel}

Particle analysis

The mean diameters of THC-SLNs in the dispersion and blank SLNs were measured with appropriate dilutions with distilled water (1:20) using Delsa ${ }^{\mathrm{TM}}$ Nano C (Beckman Coulter, California, USA). It is based on photon correlation spectroscopy, which determines particle size by measuring the rate of fluctuations in laser light intensity scattered by particles as they diffuse through a fluid. 


\section{Zeta potential}

Zeta potential was determined by using Delsa ${ }^{\mathrm{TM}}$ Nano C (Beckman Coulter, California, USA). It measures the electrophoretic movement of the particles under an applied electric field from the doppler shift of scattered light at $25^{\circ} \mathrm{C}$.

\section{Transmission electron microscopy (TEM)}

THC-SLNs were observed microscopically using TEM (H-7500, Hitachi Ltd., Japan) for uniformity of size, shape and physical stability characteristics i.e. aggregation or irregularity, at an accelerated voltage of $80 \mathrm{kV}$. A drop of the sample appropriately diluted (1/20) was placed on a carbon-coated copper grid to leave a thin film on the grid. Excess of the solution was drained off with a filter paper. The grid was air dried thoroughly and samples were viewed under TEM (20000x and 200000x), for various morphological attributes and particle size.

\section{Total drug content (TDC) and entrapment efficiency (EE)}

Total drug content (TDC) of THC-SLNs dispersion and THC-SLNs gel was determined by disrupting $1 \mathrm{ml}$ of dispersion and $1 \mathrm{~g}$ of gel using mixture of chloroform: methanol (1:1). Latter was centrifuged at $5000 \mathrm{rpm}$ to obtain a clear solution which was filtered $(0.2 \mu \mathrm{m})$ and analysed spectrophotometrically at $\lambda_{\max }$ of $282 \mathrm{~nm}$ using chloroform: methanol (1:1) as blank. Total drug content was calculated from the standard calibration curve.

The entrapment efficiency (EE) of the prepared THC-SLNs dispersion and THC-SLNs hydrogel was determined by using a dialysis membrane having pore size $2.4 \mathrm{~nm}$, molecular weight cut off 12-14 Kda. Membrane was soaked in double-distilled water for 12 hours prior to use. The SLNs dispersion $(1 \mathrm{~mL})$ and the hydrogel $(1 \mathrm{~g})$ was placed in this pre-soaked dialysis tubing, which was hermetically sealed, and dialyzed against methanol $(50 \mathrm{~mL})$ at room temperature for 45 minutes. The amount of drug released into the receptor/release medium was analysed 
spectrophotometrically with appropriate dilutions. The SLNs and hydrogel retained in the dialysis bag were disrupted using mixture of chloroform and methanol (1:1) to calculate the amount of drug entrapped within THC-SLNs and its hydroge ${ }^{27}$. Entrapment efficiency was calculated using the following expression.

$$
\text { Entrapment efficiency }(\%)=\frac{\text { Entrapped drug content }(\mathrm{mg})}{\text { Actual drug content }(\mathrm{mg})} \times 100
$$

\section{Differential scanning calorimetry (DSC)}

DSC was performed with a Perkin-Elmer Differential Calorimeter. DSC is a tool to investigate the melting and recrystallization behaviour of crystalline materials like SLNs. The breakdown or fusion of the crystal lattice by heating or cooling the sample yields information about the internal polymorphism, crystal ordering, or glass transition processes. It uses the fact that different lipid modifications possess different melting points and enthalpies. The thermal analysis of the pure drug, lipid, physical mixture and THC-SLNs was done to observe for any significant changes in the pattern of the peaks. Samples were placed in a conventional aluminium pan and heated from $10^{\circ} \mathrm{C}$ to $250^{\circ} \mathrm{C}$ at a scan speed of $10{ }^{\circ} \mathrm{C} /$ minutes $^{28}$.

$X$-ray diffraction studies $(X R D)$

$\mathrm{XRD}$ is an advanced and potential technique based on scattered intensity of an X-Ray beam, hitting a sample as a function of incident and scattered angle, polarization and wavelength or energy. The versatility and non-destructive operational procedures of the technique exhibits the crystallographic structure of the raw samples with its finished products ${ }^{29}$.

Powder X-Ray diffraction patterns of THC-SLNs, lipid and pure drug were recorded using XPERT-PRO diffractometer system, using $\mathrm{Cu}, \mathrm{K}_{\alpha}$ and $\mathrm{K}_{\beta}$ radiations at $45 \mathrm{kV}, 40 \mathrm{~mA}$ and a temperature of $25^{\circ} \mathrm{C}$. The samples were analyzed between $2 \Theta$ angles of over $5-50{ }^{\circ} \mathrm{C}$. 


\section{Determination of $\mathrm{pH}$ and rheology}

$\mathrm{pH}$ of the gel was determined using glass electrode $\mathrm{pH}$ meter (Pico+, Lab India). Rheology of the prepared gel was determined using cone and plate type rheometer (Rheolab QC, Anton Paar GmbH, Vienna, Austria) attached with water jacket (C-LTD80/QC) for maintaining constant temperature. Data analysis was carried out using Rheoplus/32 version 3.40. ACC27 spindle geometry was used for measuring the torque as well as viscosity of the sample. Temperature was kept at $30{ }^{\circ} \mathrm{C}$ and shear rate was selected from 0 to $100 \mathrm{~s}^{-1}$.

Other rheological characteristics i.e. stickiness and force of extrusion of the formulation were evaluated using TTC spreadability rig, fitted on texture analyzer ${ }^{\mathrm{TM}}(\mathrm{M} / \mathrm{s}$ stable micro systems ltd., UK). Approx. $10 \mathrm{~g}$ of formulation was placed into the lower cone of the instrument and pressed to remove any air pockets (entrapped air). Excess formulation was scrapped off to leave a flat test area.

Before testing, the upper cone probe was calibrated against lower cone so that the starting point was at same height for each test approx $25 \mathrm{~mm}$ above to lower cone. During testing the upper conical probe penetrated into the sample and continued to a depth of $2 \mathrm{~mm}$ above the sample holder surfaces i.e. probe moved a distance of $23 \mathrm{~mm}$ from its starting point (test speed $3 \mathrm{~mm} / \mathrm{sec}$ ). The force encountered by the upper cone probe to break away from gel when starting to ascend (the point of maximum force) was taken as the measurement of gel strength; the higher the value, better is the strength of gel network. The area of the curve upto this point was taken as measurement of work of shear, reflecting the work of spreadability of the sample. The negative region of the graph, produced on the return of the probe, was a result of the weight of the sample which is lifted primarily on the upper surface of the cone. Latter is evident due to its back movement and hence provides an indication of adhesion or resistance to flow off the disc. The maximum negative region 
of the curve was taken as work of adhesion of the gel and it represents the force required to extrude from the tube.

\section{Occlusion testing}

The occlusive properties of THC-SLNs gel, Tacroz ${ }^{\circledR}$ Forte, blank SLNs gel and blank gel without SLNs $(n=3)$ were evaluated by in vitro occlusion test ${ }^{30}$. Preweighed beakers $(100 \mathrm{~mL}$ each) with an internal diameter of $4.9 \mathrm{~cm}$ were taken and filled with $50 \mathrm{~mL}$ of water and subsequently covered with Whatman filter paper. The formulations were uniformly spread evenly on the surface using a spatula. The beakers were then stored at $32 \pm 0.5^{\circ} \mathrm{C}$ (to mimic the temperature of the skin surface) for 48 hours. Beakers were weighed at 24 , and 48 hours. The percent water loss was quantified and occlusion factor $(\mathrm{F})$ was calculated by the following Equation.

$$
F=\frac{A-B}{A} \times 100
$$

Where $\mathrm{F}$ is the occlusion factor, $\mathrm{A}$ is the water loss without sample (reference) and $\mathrm{B}$ is the water loss with sample.

\section{Stability studies}

The stability studies were performed in accordance to the ICH guidelines ${ }^{31}$. THC-SLNs dispersion was kept at $4{ }^{\circ} \mathrm{C} \pm 3{ }^{\circ} \mathrm{C}$ and $40{ }^{\circ} \mathrm{C} \pm 2{ }^{\circ} \mathrm{C} / 75 \% \mathrm{RH} \pm 5 \% \mathrm{RH}$ while THC-SLNs gel was stored at 25 ${ }^{\circ} \mathrm{C} \pm 2{ }^{\circ} \mathrm{C} / 60 \% \mathrm{RH} \pm 5 \% \mathrm{RH}$ and $40{ }^{\circ} \mathrm{C} \pm 2{ }^{\circ} \mathrm{C} / 75 \% \mathrm{RH} \pm 5 \% \mathrm{RH}$ respectively and were analysed

for total drug content, entrapment efficiency, particle size, and visual changes for 0-2 months. Further, long term stability studies are planned to be carried out.

In-vitro drug release

In-vitro drug release was performed using dialysis membrane having pore size $2.4 \mathrm{~nm}$, molecular weight cut off $12-14 \mathrm{Kda}$. The membrane was equilibrated using the release media ( $2 \%$ tween 80 
$+10 \%$ ethanol $+15 \%$ isopropyl alcohol buffer in phosphate buffer $\mathrm{pH} 7.4$ ) prior to the experiment. The media $(50 \mathrm{~mL})$ was stirred at $50 \mathrm{rpm}$ throughout the experiment, using a magnetic stirrer. Temperature was maintained at $32 \pm 0.5{ }^{\circ} \mathrm{C}$ during the whole experiment. THC-SLNs dispersion (0.25 mL), THC-SLNs gel $(500 \mathrm{mg})$, free THC in gel $(500 \mathrm{mg})$, all containing $940 \mu \mathrm{g}$ of THC were loaded on the dialysis membrane. Samples $(3 \mathrm{~mL})$ were withdrawn at 15 minutes, 30 minutes, $1,2,4,6,8,10,12$, and 24 hours. Volume of sample withdrawn was replaced with an equal volume of fresh receptor medium. The experiments were carried out for 24 hours. All measurements were done in triplicate at $282 \mathrm{~nm}$. The mechanism of drug release was determined by fitting the release data to several release kinetic models.

\section{Ex-vivo skin permeation studies}

Jacketed Franz glass diffusion cells were used for the determination of permeability of THC and its SLNs formulations through pig ear skin. Pig ears were obtained post-sacrifice from a local abattoir before the pig carcass was exposed to the normal high-temperature cleaning procedure. The subcutaneous fat tissue was removed, and hair present was trimmed carefully as short as possible using scissors without damaging or scratching the surface in order to ensure the integrity of the skin barrier. The barrier integrity of the skin was checked by measuring the transepidermal water $\operatorname{loss}^{32}$ and criteria for inclusion/exclusion of the skin sample for the studies was set. Excised skin was then carefully mounted on the diffusion cell ${ }^{33}$. These cells consist of the donor and the receptor chambers between which the skin is positioned. Average area of skin in contact with the receptor medium was $3.14 \mathrm{~cm}^{2}$ and the average receptor chamber volume was $30.0 \mathrm{~mL}$. Circular ear skin pieces equal to or slightly greater than the size of external circumference of donor compartment were cut out $(n=6)$ and mounted onto the diffusion cell assembly, keeping the stratum corneum side towards the donor compartment and the dermal side in contact with the 
receptor fluid. The whole system was water jacketed and thermostatically controlled by an external circulating water bath at $32 \pm 0.5{ }^{\circ} \mathrm{C}$. The receptor media $(2 \%$ tween $80+10 \%$ ethanol $+15 \%$ isopropyl alcohol buffer in phosphate buffer $\mathrm{pH}$ 7.4) was stirred at $50 \mathrm{rpm}$ throughout the experiment, using a magnetic stirrer. Mounted skin was allowed to equilibrate for 2 hours, after which the receptor media was replaced with fresh media. This was done to remove any water soluble UV absorbing materials present in or released from the skin, which could interfere with the UV spectrophotometric readings of the drug. THC-SLNs dispersion $(0.25 \mathrm{~mL})$, THC-SLNs hydrogel (500 mg), THC gel (500 mg), all containing $940 \mu \mathrm{g}$ of THC along with their respective blank formulations were applied evenly onto the donor side of the skin surface and the donor cell was covered with aluminium foil to prevent losses due to evaporation. $1.0 \mathrm{~mL}$ aliquots were withdrawn from the receptor compartment, at different time intervals starting at 15 minutes, 30 minutes, 1, 2, 4, 6, 8, 10, 12, and 24 hours. The volume of sample withdrawn was replaced with an equal volume of fresh receptor medium. The experiments were carried out in triplicate for 24 hours.

At the end of permeation studies ( 24 hours), the skin surface was wiped with a moist cotton swab several times ( 6 times) to remove any residual formulation sticking to the skin. The cotton swabs were then put into $10 \mathrm{~mL}$ of methanol and vortexed to solubilise and determine the amount of drug left on the skin by measuring the absorbance of this solvent after filtration at $282 \mathrm{~nm}$. The skin was cut into small pieces and kept in methanol $(50 \mathrm{~mL})$ for 24 hours for extraction of the drug in the solvent. Latter was then centrifuged and filtered prior to the estimation of drug content by UV spectrophotometer at $282 \mathrm{~nm}$ (linearity range $0.5-20 \mu \mathrm{g} / \mathrm{mL}$ ). Similar procedure was repeated for blank (skin without any formulation) so as to determine the amount of drug permeated across stratum corneum. 
The flux was obtained by plotting the cumulative amount of drug(s) in the receptor phase/sq. $\mathrm{cm}$. of the skin against time. Steady state slope obtained by linear regression of cumulative amount/sq.cm versus time plot gives the flux value.

Acute dermal irritation studies

Acute dermal irritation study was performed in accordance with the OECD guideline $404^{31}$. Rabbits (Albino) were divided into two groups $(n=3)$. One served as control, while the other served as treatment group.

For the preparation of the animals, approximately 24 hours before the test, furs of the animals were removed by closely clipping the dorsal area of the trunk of the animals. Care was taken to avoid abrading the skin, and only the animals with healthy, intact skin were used.

Animals were housed individually and were exposed to normal day light cycle. For feeding, conventional laboratory diet was used with an unrestricted supply of drinking water.

\section{Test procedure}

Application of the test substance (THC-SLNs gel)

THC-SLNs gel $(0.5 \mathrm{~g})$ was applied to a small area (approximately $\left.6 \mathrm{~cm}^{2}\right)$ of skin. At the end of the exposure period, which was 4 hours, residual test substance was removed. Scores for erythema and oedema were recorded in accordance to the scoring system referred in the guidelines ${ }^{34}$.

\section{In vivo pharmacodynamic activity}

Male lacca mice bred in Central Animal House facility of Panjab University, Chandigarh, weighing $20-40 \mathrm{~g}$ were used. The animals were housed under standard light/ dark cycle with food and water provided ad libtum. Animals were acclimatized to laboratory condition before test. The experiments were performed between 09.00 and 17.00 hours. The experimental protocol was approved by the Institutional Animal Ethics Committee of the institute (PU/IAEC/S/14/59). 


\section{Excision wound mice model}

The animals were divided into 5 groups $(n=6)($ Table 1$)$. The fur of the animals was removed and skin was sterilised using $70 \%$ alcohol. The animals were anaesthetised using ether. Further, a full thickness excision wound of $1 \mathrm{~cm}$ diameter was made using sharp scissors. Topical treatment with the formulation was started from day 2 . The observations were made for visual changes starting from initiation of treatment $\left(2^{\text {nd }}\right.$ day) till the final day ( $14^{\text {th }}$ day) of observation ${ }^{35}$ and percentage wound closure was determined by the formula.

$$
\text { Percentage wound healing }=\frac{\text { Initial area }- \text { nth day area } \times 100}{\text { Initial area }} .
$$

\section{Biochemical estimation}

\section{Preparation of tissue homogenate}

At the end of $14^{\text {th }}$ day, the mice were sacrificed by ether inhalation. Mice skin was excised and rinsed in ice cold phosphate buffer saline ( $\mathrm{pH}$ 7.4). The homogenate of the skin $8 \%$ ( $\mathrm{g}$ of skin in volume of phosphate buffer saline) was prepared using tissue homogenizer at 5,000 rpm. It was then, centrifuged at $10,000 \mathrm{rpm}$ at $4^{\circ} \mathrm{C}$ for 10 minutes and the clear supernatants were collected and used for the following biochemical estimations of various groups. Protein estimation was performed using biuret test ${ }^{36}$. Lipid peroxidation, reduced glutathione estimation, superoxide dismutase and catalase activity was performed according to the standard referred methods $\mathrm{s}^{37,38}$.

\section{Histopathological studies}

After $14^{\text {th }}$ day of the treatment protocol, the animals were sacrificed by ether anaesthesia and treated dorsal area was excised, rinsed with ice cold phosphate buffer saline and fixed in $10 \%$ buffered formalin. The skin sections were embedded in paraffin and microtoned. The sections were stained 
with hematoxylin and eosin and observed under a high power light microscope (40x). The skin sections were evaluated for the skin integrity.

Histopathology of skin samples was carried out at Medicos Centre, Chandigarh-160022, India, under the supervision of a trained pathologist.

\section{Statistical analysis}

All the results are expressed as mean \pm standard deviation (SD). All statistical analysis was performed using graph pad prism 5. Data was analyzed using one-way ANOVA. p-Values $<0.05$ were considered as statistically significant.

\section{Results}

THC-SLNs were prepared successfully by microemulsification method ${ }^{26}$, which is a spontaneous workable method at lab scale, wherein the crystallisation of hot melt lipid occurs in cold water (2$8{ }^{\circ} \mathrm{C}$ ), kept under stirring. It is noteworthy to highlight here, that though microemulsions usually contain high surfactant (Tween 80$)\left(30 \%\right.$ or above) and co-surfactant $(5-10 \%)$ concentrations ${ }^{39}$, however, the THC-SLNs hydrogel was optimized suitably to meet the specifications laid by USFDA for inactive ingredients (Tween $80: 7.50 \%$ and phosphatidylcholine: $0.50 \%$ ). Compritol ${ }^{\circledR}$ 888 ATO was chosen as the lipid component of the SLNs as it is indicated to result in stable dispersions with small particle size $\mathrm{e}^{40}$.

\section{Characterization of THC-SLNs and gel}

\section{Particle size analysis}

Mean particle size of THC-SLNs was estimated to be $96.60 \mathrm{~nm}$ with a polydispersity index of 0.252, indicating a narrow particle size distribution while the mean particle size of blank SLNs was found to be $102.40 \mathrm{~nm}$ with a polydispersity index of 0.299 . It is evident that incorporation of 
THC did not significantly alter the particle size of the nanoparticles. The small particle size obtained with both blank and drug loaded SLNs may be attributed to the presence of satisfactory surfactant and co-surfactant concentration that results in reduction in the surface tension and production of particles with small sizes ${ }^{[41-43]}$.

\section{Zeta potential}

Zeta potential of THC-SLNs and blank SLNs measured by employing Delsa nano zetasizer at 25 ${ }^{\circ} \mathrm{C}$ was found to be $-22 \mathrm{mV}$ and $-15 \mathrm{mV}$ respectively. High negative charge indicate towards formation of a stable nano particulate system with lower chances of aggregation post storage for prolonged time period ${ }^{44}$. The negative charge can be associated with the presence of hydroxyl ions on the surface of the lipid nanostructures, and is consistent with the observations in the previous studies $^{45}$.

\section{TEM}

TEM showed uniform particles in the of size range of $35-175 \mathrm{~nm}$, thus confirming to the size as observed by photon correlation spectroscopy (PCS) as given in Figure 1. The particles were ellipsoidal in shape with no aggregation and/or irregularity in the structure of the THC-SLNs.

\section{Total drug content (TDC) and entrapment efficiency (EE)}

TDC of THC-SLNs dispersion and THC-SLNs gel was estimated to be $94.51 \% \pm 2.15 \%$ and $99.68 \% \pm 0.51 \%$ respectively. High values of TDC are indicative of the insignificant losses incurred during the processes of preparation of THC-SLNs by microemulsification technique ${ }^{46}$. The entrapment efficiency of prepared THC-SLNs and THC-SLNs gel was found to be $69.56 \% \pm$ $1.35 \%$ and $65.95 \% \pm 0.14 \%(n=6)$ respectively. Higher EE indicates the suitability of the method used for the preparation of SLNs. 
pH and Rheology

The $\mathrm{pH}$ value of THC-SLNs gel was found out to be in range of $6.68 \pm 0.21$, permitting the safe use of the gel on the skin. The yield value of the THC-SLNs gel was found to be $13.88 \mathrm{~Pa}$ which represents its good fluid strength ${ }^{47}$. The value of $n$ (which indicates the shear thinning or shear thickening property of the gel) was less than $1(n=0.290)$, which corroborates the shear thinning nature of the THC-SLNs gel ${ }^{48}$. THC-SLNs gel exhibited consistency index of 77.40 Pa.s, thus affirming good spreadability which is a desirable feature of a topical formulation ${ }^{49}$.

THC-SLNs gel also displayed fairly good gel strength with a low work of shear, and force of extrusion was found to be less than a marketed gel formulation (aceclofenac gel) suggesting the ease of extrudability from the collapsible tube. Though stickiness (sign of adhesiveness) was found to be less than the marketed formulation yet it was enough to hold the formulation at the site of action for a long time. As a comparison with gel was to be made, and in absence of any THC gel in the market, aceclofenac gel was used for comparison of rheological properties of the prepared SLN hydrogel.

$D S C$

THC (Figure 2A) showed a melting endotherm at $95{ }^{\circ} \mathrm{C}$, which corresponds to its melting point with an enthalpy of $126.30 \mathrm{~J} / \mathrm{g}$, while Compritol $^{\circledR} 888$ ATO, (Figure 2B) showed a sharp peak at $73.06{ }^{\circ} \mathrm{C}$ and an enthalpy of $122.60 \mathrm{~J} / \mathrm{g}$. THC-SLNs dispersion (Figure 2D), however, showed a broad endotherm at a lower temperature starting from $55{ }^{\circ} \mathrm{C}-68.8{ }^{\circ} \mathrm{C}$ (enthalpy of $54.87 \mathrm{~J} / \mathrm{g}$ ) confirming encapsulation of THC into the lipid nanoparticles as no peak was observed corresponding to that of $\mathrm{THC}$ or lipid whereas distinct peaks at their respective melting points were observed in simple physical mixture of Compritol ${ }^{\circledR} 888$ ATO and THC, (Figure 2C). Also melting endotherm of Compritol ${ }^{\circledR} 888$ ATO in THC-SLNs was depressed as compared to the bulk 
Compritol $^{\circledR} 888$ ATO suggesting a less stable $\alpha$ or $\beta$ form of triglycerides in SLNs. This melting point depression may be due to their small particle size (nanometer range), high specific surface area and the presence of a surfactant.

$X R D$

The X-ray diffraction pattern of pure Compritol ${ }^{\circledR} 888$ ATO shows sharp peaks at $21^{\circ}$ and $23^{\circ}$ due to lipidic polymorphism, Figure 3 represents the crystalline nature of the (A) lipid and the (B) drug. Figure $3 \mathrm{~B}$ also shows distinct peak at $17^{\circ}$, however upon incorporation of THC into SLNs no such peak was observed (Figure 3C), indicating the amorphous nature of the prepared SLNs. The amorphous nature is further responsible for the controlled release of the drug from THC$\mathrm{SLNs}^{50}$. However, no characteristic peaks in BSLNs indicate the amorphous nature of lipid after transformation into SLNs.

\section{Occlusion testing}

Percentage water loss exclusively depends on the ability of the formulation to form an occlusive layer on the skin. There was almost 2 times more percent water loss through the filter paper at the end of 24 and 48 hours for THC-SLNs gel was twice as compared to the Tacroz ${ }^{\circledR}$ Forte. Latter is attributed to the high emollient effect of the ointment base of the Tacroz ${ }^{\circledR}$ Forte as compared to the THC-SLNs hydrogel. Further, there was no significant difference between the blank SLNs gel and THC SLNs gel. The occlusivity offered by THC-SLNs gel and blank SLNs gel could be attributed to solid nature of the lipid component which form an intact lipid film on filter paper surface. The skin occlusivity offered by THC-SLNs gel would be helpful for mitigating the symptoms like itching, dryness and scaling which are the main prompters for induction of dermatitis $^{33}$. In contrast to this, blank Carbopol ${ }^{\circledR} 934$ gels without any SLNs had lowest occulsion factor because of highest water flux due to absence of any lipids in the formulation. This in 
confirmation with previous reports on blank Carbopol ${ }^{\circledR} 934$ gels $^{33}$. The occlusion factor measured after 24 and 48 hours for THC-SLNs gel, Tacroz ${ }^{\circledR}$ Forte, blank SLNs gel and blank Carbopol ${ }^{\circledR}$ 934 gel are given in table 2.

In-vitro drug release

In vitro drug release studies were performed with the developed THC-SLNs gel, free THC and THC-SLNs dispersion (Figure 4A). THC-SLNs dispersion showed a significantly higher and fast drug release $(p \leq 0.05)$ at all evaluation points in comparison to the free drug. The release of THC from THC-SLNs gel and SLNs dispersion was almost 16-17 times higher than the free THC hydrogel. The release kinetics of THC from THC-SLNs dispersion obeyed Korsmeyer-peppas model (non-fickian mechanism) while the drug release pattern from the THC-SLNs gel followed Higuchi's equation indicating the release of drug from hydrogel as a square root of time dependent process based on Fickian diffusion ${ }^{51}$.

Ex-vivo permeation

In order to assess the skin permeation and localization of THC from THC-SLNs, the ex-vivo permeation ability through porcine ear skin was investigated. The comparative amount of drug permeated from all the formulations is given in Figure 4B. The effect of gel as a carrier on accumulation and diffusion of THC through the skin was evaluated using ex-vivo skin permeation studies. During this study, the permeation data of THC-SLNs gel was compared with free THC gel and THC-SLNs dispersion per se. THC-SLNs gel displayed significantly higher drug permeation at all the sampling times (almost 8.4 fold as compared to free THC gel). A flux value of $0.11 \pm 0.03 \mu \mathrm{g} / \mathrm{h} / \mathrm{cm}^{2}$ was obtained, with topical application of free THC gel which was 13.75 times lower than THC-SLNs $\left(1.54 \pm 0.42 \mu \mathrm{g} / \mathrm{h} / \mathrm{cm}^{2}\right)$ dispersion and 9.19 times lower than THCSLNs gel $\left(1.03 \pm 0.33 \mu \mathrm{g} / \mathrm{h} / \mathrm{cm}^{2}\right.$ respectively). Permeability coefficient $\left(\mathrm{K}_{\mathrm{p}}\right)$ obtained for THC- 
SLNs was 12.60 times higher than free THC gel while the THC-SLNs hydrogel showed a 8.46 times higher $K_{p}$ value in comparison to free THC gel. There was significant difference $(p \leq 0.05)$ in the values obtained for free THC gel and THC-SLNs hydrogel.

Skin deposition of THC in pig ear skin from THC-SLNs gel was compared with the free THC gel. There was a significant difference $(p \leq 0.05)$ in the THC accumulation between the two formulations (> 13\%). THC-SLNs gel displayed significantly higher deposition of drug in the skin $(202.72 \pm 25.45 \mu \mathrm{g})$. On the other hand, free THC gel showed depleted deposition of the drug $(15.04 \pm 3.86 \mu \mathrm{g})$ in the skin. The quantification of drug remaining unabsorbed at the end of 24 hours showed almost 1.74-fold higher drug on the skin surface in case of free THC gel as compared with the THC-SLNs gel. This signifies the importance of incorporating THC into SLNs for increasing its penetration as a result of enhanced solubility and small particle size.

\section{Stability studies}

The THC-SLNs dispersion and the final formulated THC-SLNs gel were stable at various storage conditions. There was insignificant change $(\mathrm{p} \leq 0.05)$ in particle size, total drug content and entrapment efficiency of THC-SLNs and THC-SLNs gel at $4{ }^{\circ} \mathrm{C} \pm 3{ }^{\circ} \mathrm{C}, 25{ }^{\circ} \mathrm{C} \pm 2{ }^{\circ} \mathrm{C} / 60 \% \mathrm{RH} \pm$ $5 \% \mathrm{RH}, 40{ }^{\circ} \mathrm{C} \pm 2{ }^{\circ} \mathrm{C} / 75 \% \mathrm{RH} \pm 5 \% \mathrm{RH}$ as given in Tables $3 \mathrm{~A}$ and $\mathrm{B}$. Though increase in the particle size was observed, however it was below $200 \mathrm{~nm}$, required for enhanced permeation across the stratum corneum ${ }^{52}$. Latter may be assigned to the fact that on cooling SLNs, lipids are not fully crystallized and carbon chains are freezed heterogeneously. With time, carbon chains change their orientation and start forming crystals leading to a change in shape of SLNs which exposes new surfaces that are not coated with surfactant. These uncoated surfaces which are sticky lead to aggregation of $\mathrm{SLNs}^{53,33}$. 
Acute dermal irritation studies

OECD guideline 404 was followed for acute dermal irritation studies ${ }^{34}$. The formulation was applied for 4 hours and was evaluated after 1, 24, 48 and 72 hours of application. No skin reaction such as erythema and edema was observed in animals for any group.

\section{In-vivo pharmacodynamic study}

\section{Excision wound mice model and histopathological study}

The in vivo wound healing potential of the THC-SLNs gel was assessed in comparison with the free THC gel using the excision wound mice model ${ }^{54}$. Representative images of the excision wound with the histopathology are depicted in Figure 5 (A1-A10). The positive control (A3 and A8) and free THC gel (A4 and A9) demonstrated delayed healing processes compared to naive (untreated normal skin) control group (A1 and A6), THC-SLNs hydrogel treated group (A2 and A7) and blank SLNs gel (A5 and A10). As compared to the positive control (untreated wounds) (A3 and A8), the reduction in wound sizes was significantly higher when THC-SLNs gel (A2 and A7) was used.

The histological study of the skin of positive control animals, Figure 5(A8) shows the absence of an intact layer of epidermis and presence of necrotic tissue. Disruption of epidermis, showed absence of healing. Visible signs of inflammation in deeper layers i.e., muscles and blood vessels were present along with inflammatory exudates, Figure 5(A8 and A1).

Treatment with THC-SLNs gel shows the intact epidermis and normal dermis with no signs of inflammation, Figure 5(A7) as compared to free THC gel, Figure 5(A9). There was an increase in the collagenous mass at the site of injury indicating regeneration and repair of the tissue. In contrast, immature and disorganized epidermal layers due to delay in full-thickness reepithelialisation, fewer and less obvious areas of blood vessels were noted throughout the scantly 
formed granulation tissue of the untreated mice Figure 5(A8). This was further characterized by few fibroblasts, less dense collagen fibres. Whereas, more distinct, thick, densely associated and well organized collagen fibres/bands with normal fibroblasts alignment and persistence of inflammatory cells were found in late granulation tissue of the mice post application of THC-SLNs gel, in comparison to free THC gel and blank SLNs gel.

\section{Biochemical estimation}

\section{$L P O$}

In positive control mice, there was a significant increase $(\mathrm{p}<0.005)$ in the MDA levels $(2.86$ times) as compared to naive mice. In contrast, groups treated with $0.2 \% \mathrm{w} / \mathrm{w}$ of THC-SLNs gel and blank SLNs gel, showed a reduction of MDA levels by $60 \%$ and $47.60 \%$ respectively. Furthermore, both these groups produced complete reversal in the elevated MDA levels such that the values were similar $(\mathrm{p}<0.05)$ to those obtained for the naïve control groups (Figure 6A). Free THC gel however did not show any significant effect on MDA levels.

\section{Reduced glutathione}

There was a significant reduction $(\mathrm{p}<0.05)$ in GSH levels in positive control (Figure 6B) as compared to naïve mice (negative control). Treatment with $0.2 \% \mathrm{w} / \mathrm{w}$ THC-SLNs gel increased GSH levels by 2.23 times. However, free THC gel at similar concentrations did not show any significant increase in GSH levels.

SOD assay

The treatment with THC-SLNs gel significantly increased the SOD level, (Figure 6C) reduces oxidative stress and ROS generation which indicates its protective role. SOD levels decreased in the positive control group by 9.45 times compared to naive mice. In groups treated with $0.2 \% \mathrm{w} / \mathrm{w}$ THC-SLNs gel, SOD levels were increased by 7.60 times. However, $0.2 \% \mathrm{w} / \mathrm{w}$ free THC gel and 
blank SLNs gel did not show any significant increase $(\mathrm{p}<0.05)$ in SOD as compared to the THCSLNs gel treated groups.

\section{Catalase assay}

Catalase levels decreased in the positive control by 2.21 times compared to naive mice (Figure 6D). In groups treated with $0.2 \% \mathrm{w} / \mathrm{w}$ THC-SLNs gel, catalase levels were increased by 2.02 times. However, $0.2 \% \mathrm{w} / \mathrm{w}$ free THC gel did not show any significant increase $(\mathrm{p} \leq 0.05)$ in catalase levels as compared to the THC-SLNs group.

\section{Discussion}

Tetrahydrocurcumin, a stable, hydrogenated product of curcumin has remained as an underexplored molecule to be developed as a topical therapeutic for skin inflammation. Nanotailoring the molecule can improve its aqueous solubility, permeation and retention onto the surface of the skin and can make the molecule bioavailable at the site of application.

Drug permeation across the skin depends on ability of the drug to diffuse out of the vehicle and its penetration through the external cornifying layer (stratum corneum) of the $\operatorname{skin}^{55,56}$. Use of phosphatidylcholine to increase drug transport across rat skin has been reported at much higher concentration $(10-15 \%)$ than used in THC-SLNs gel $(0.5 \%$ PC) so as to meet the Inactive Ingredient Guide (IIG) limits specified by Food and Drug Administration (FDA) ${ }^{57}$. Also, the surfactant i.e. Tween 80 is added in accordance to approved IIG limits ${ }^{58}$. The attained particle size, TDC and EE confirmed the suitability of the microemulsification technique for loading white curcumin into lipidic nanoparticles.

TEM examination revealed the existence of particles with ellipsoidal to disc-like shape. DSC and X-Ray diffraction studies confirmed the formation of amorphous THC-SLNs. The ideal occlusivity offered by THC-SLNs gel was assigned to the ability of lipidic nanoparticles to form 
an adhesive layer upon dermal application and thus occluding the skin surface to avoid the loss of water $^{59}$. As a result, with the enhanced hydration of stratum corneum, the loosening of corneocytes packing occurs, which widens the intercorneocyte gap thus facilitating the drug penetration into deeper skin strata ${ }^{60}$. Rheological evaluation of THC-SLNs gel showed appropriate consistency and viscosity to adhere and self-immobilize for an easy application on the skin. The results obtained in in vitro studies were corroborated with in vivo pharmacodynamic studies. The Higuchian release by THC-SLNs gel indicates the pathway of the drug release from the inside of lipid matrix to the surface of SLNs and then the outside aqueous phase ${ }^{61}$. Ex vivo permeation studies significantly showed an approximately 17 times higher flux, indicating the ability of small lipidic nanoparticles to cross the skin and reach the site of inflammation. The formulation was non-staining, nonirritating, non-greasy and easy spreadable as revealed by the acute dermal irritation testing studies (OECD 404). This makes the product patient compliant and more acceptable for its use, as compared to the topical products of the parent molecule curcumin which stain the skin on topical application.

The results of the excision wound mice model highlighted that THC-SLNs gel, not only possesses anti-oxidant, anti-inflammatory activity but also holds an excellent wound healing potential. Owing to accelerated epithelialisation, cellular proliferation, formation of granulation tissue, synthesis of collagen tissue, topical application of THC at the wound site produced significant wound healing activity, which may be due to its angiogenic potential. These progressive changes in the epidermal and dermal architecture include: keratinization and full-thickness epidermal regeneration, which covered largely the wound area, intense improvement in the maturation and organization of epidermal layers with no debridement crust covering the epidermal surface, an increase in deposition and organization of extracellular matrix elements. 
Wound healing was faster and better in the decreasing order: THC-SLNs gel $>$ free THC gel $>$ positive control. Wound healing rate was significantly higher $(\mathrm{p} \leq 0.05)$ in THC-SLNs gel treated animals than those treated with free THC gel. THC-SLNs gel left no prominent scar at the wound site, pointing towards the enhanced bioactivity of THC post incorporation into $\mathrm{SLNs}^{62}$. Latter was confirmed by the histological investigations, which revealed a complete healing of skin on application of THC-SLNs gel. Similar study reported by Rao et al. (2015) reported the usefulness of glucosylated THC in the process of wound healing ${ }^{63}$. They also confirmed its enhanced percutaneous absorption and potent in vivo wound healing effect. Latter study indicated the role of glycosyl moiety to improve upon the aqueous solubility of THC which subsequently enhances the therapeutic activity of THC. While the bioenhanced activity of THC in our study is assigned to the nanocoutured THC which due to the small particle size exhibits enhanced skin permeation thus highlighting the significance of incorporating the drug into lipidic nanoparticles ${ }^{33}$. The enhanced antioxidant potential of THC-SLNs gel indicated by a significantly decreased MDA (2.22 times), increased GSH (2.23 times), SOD (7.60 times) and catalase (2.02 times) levels visa-vis free THC gel, are a proof to the biochemical in vivo activity post topical application. Interestingly, blank SLNs gel also showed some antioxidant properties. This could be due to presence of phosphatidylcholine in the SLN formulation. Use of phosphatidylcholine for a long duration of time is reported to result in decrease in MDA levels ${ }^{64}$. Since, phosphatidylcholine containing SLNs gel, was applied continuously for a time period of 14 days, it could probably be responsible for the observed decreased levels of MDA. Additionally, presentation of phosphatidylcholine $(2 \%)$ as highly bioavailable SLN formulation would have added to its efficacy $^{64,65}$. Similar results have been reported in a study by Kadoma and Fujisawa (2007). They revealed that THC oxidized by peroxy radicals may be more antioxidative than curcumin in the 
interplay with $\mathrm{GSH}^{66}$. In another study, THC was reported to be a better molecule for the inhibition of phospholipase A2, a substrate for proinflammatory mediator than curcumin i.e. prostaglandins; (which are involved in the process of skin inflammation ${ }^{66}$. These in vitro and in vivo studies are indicative of the efficacy of THC-SLNs for all the categories of skin ailments.

To the best of our knowledge, this is the first paper highlighting the therapeutic effectiveness of nano-lipidic particles of THC. The in vitro and in vivo studies are indicative of the efficacy of THC-SLNs for all the categories of skin ailments with inflammation. This product is expected to be a one of its kind with its ability to cater to inflammatory condition of the skin of not only the adults but paediatric population as well ${ }^{67}$. Till now, there are no products available for the chronic conditions like dermatitis in the market. The available products belong to the category of steroids, antibiotics and calcineurin inhibitors and the use of these products is associated with serious side effects $^{68}$. Thus, THC-SLNs gel would present safer alternative to the currently available products in the market and provide ease to the patients with chronic skin inflammation. Further studies are necessary to investigate the exact mechanisms related to the findings of the study. Prospective studies to confirm the concentration/presence of the THC in the various layers of the skin, which include the confocal microscopic studies and dermatokinetic modelling are warranted and planned as future protocols.

\section{Acknowledgement}

Authors express their sincere thanks to DST-SERB (File No: YSS/2015/000427), New Delhi, India, for their financial support. Authors are also thankful to UIPS, Panjab University, Chandigarh, for providing the necessary facilities for performing the research work and to Gajanand Sharma for helping to perform the Rheological studies.

\section{References}


1. Krausz AE, Adler BL, Cabral V, et al. Curcumin-encapsulated nanoparticles as innovative antimicrobial and wound healing agent. Nanomedicine 2015;11(1):195-206.

2. Mangalathillam S, Rejinold NS, Nair A, et al. Curcumin loaded chitin nanogels for skin cancer treatment via the transdermal route. Nanoscale 2012; 4(1):239-250.

3. Das MK, Kumar K. Development of curcumin nanoniosomes for skin cancer chemoprevention. Int J ChemTech Res 2015;7(2):747-754.

4. Xu Y, Ku BS, Yao HY, et al. The effects of curcumin on depressive-like behaviors in mice. Eur J Pharmacol 2005;518(1):40-46.

5. Kulkarni SK, Mehta AK. Purine nucleoside-mediated immobility in mice: reversal by antidepressants. Psychopharmacology (Berl) 1985;85(4): 460-3.

6. Porsolt RD, Bertin A, Jalfre M. "Behavioural despair" in rats and mice: Strain differences and the effects of imipramine. Eur J Pharmacol 1978;51(3):291-294.

7. Siviero A, Gallo E, Maggini V, et al. Curcumin, a golden spice with a low bioavailability. J herb med 2015;5(2):57-70.

8. Suri SS, Fenniri H, Singh B. Nanotechnology-based drug delivery systems. J Occup Med Toxicol 2007;2:1-6.

9. Kaur IP, Bhandari R, Kakkar V, et al. Potential of solid lipid nanoparticles in brain targeting. J Control Release 2008;127(2):97-109.

10. Kakkar V, Muppu SK, Chopra K, et al. Curcumin loaded solid lipid nanoparticles: an efficient formulation approach for cerebral ischemic reperfusion injury in rats. Eur J Pharm Biopharm 2013;85(3 Pt A):339-45. 
11. Kakkar V, Kaur IP. Evaluating potential of curcumin loaded solid lipid nanoparticles in aluminium induced behavioural, biochemical and histopathological alterations in mice brain. Food Chem Toxicol 2011;49(11):2906-13.

12. Zhao YZ, Lu CT, Zhang Y et al. Selection of high efficient transdermal lipid vesicle for curcumin skin delivery. Int J Pharm 2013;454(1):302-309.

13. Liu CH, Chang FY. Development and Characterization of Eucalyptol Microemulsions for Topic Delivery of Curcumin. Chem Pharm Bull 2011;59:172-8.

14. Sintov AC. Transdermal delivery of curcumin via microemulsion. Int J Pharm 2015;481(12):97-103.

15. Nakamura Y, Ohto Y, Murakami A, et al. Inhibitory Effects of Curcumin and Tetrahydrocurcuminoids on the Tumor Promoter-induced Reactive Oxygen Species Generation in Leukocytes in vitro and in vivo. JPN J Cancer Res 1998;89:361-70.

16. Osawa T, Sugiyama $\mathrm{Y}$, Inayoshi $\mathrm{M}$, et al. Antioxidative activity of tetrahydrocurcuminoids. Biosci Biotechnol Biochem 1995;59(9):1609-12.

17. Pan MH, Huang TM, Lin JK. Biotransformation of curcumin through reduction and glucuronidation in mice. Drug Metab Dispos 1999;27(4):486-94.

18. Plyduang T, Lomlim L, Yuenyongsawad S, et al. Carboxymethylcellulosetetrahydrocurcumin conjugates for colon-specific delivery of a novel anti-cancer agent, 4amino tetrahydrocurcumin. Eur J Pharm Biopharm 2014;88:351-60.

19. Muhammad M, Gertru C, Gabriel J, et al. A randomized, double-blind, placebo-controlled, comparative study. Household and Personal Care today 2010;3:44-6. 
20. Saipin S, Wichan K, Duangkhae M, et al. Controlled release of oral tetrahydrocutcumin from a novel self-emulsifying floating drug delivery system (SEFDDS). AAPS PharmSciTech 2011;12.

21. Dennis D, Dean E, Aynun N, et al.. J Chrom 2005;824:206-212.

22. Kashif A, Yan L, David J, et al. Nanoemulsion and emulsion based delivery systems for curcumin : Encapsulation and release properties. Food Chem 2012;132:799-807.

23. Heidegrid SK, Rilton A, Marcia M, et al. Topical curcumin loaded hydrogels obtained using galactomannan from Schizolobium parahybae and xanthan. Carbohydr polym 2015;116:229-236.

24. Fayez H, Mayyas A. Novel delivery system of curcumin through transdermal route using sub-micronized particles composed of mesoporous silica and oleic acid. $\mathrm{J}$ funct foods 2014;8C:87-99.

25. Mühlen AZ, Schwarz C, Mehnert W. Solid lipid nanoparticles (SLN) for controlled drug delivery-drug release and release mechanism. Eur J Pharm Biopharm. 1998;45:149-155.

26. Kakkar V, Singh S, Singla D, et al. Exploring solid lipid nanoparticles to enhance the oral bioavailability of curcumin. Mol nutr food res 2011;55(3):495-503.

27. Kakkar V, Singh S, Singla D, et al. Exploring solid lipid nanoparticles to enhance the oral bioavailability of curcumin. Mol Nutr Food Res 2011;55:495-503.

28. Gramaglia D, Conway B, Kett VL et al. High speed DSC (Hyper DSCTM) as a tool to measure the solubility of a drug within a solid or semi-solid matrix. Int J Pharm 2005;301:1-5.

29. Hina S, Zhang Y, Wang H. Characterization of polymeric solutions: a brief overview. Rev Adv Mater Sci 2014;36:165-176. 
30. Montenegro L, Parenti C, Turnaturi R, et al. Resveratrol-loaded lipid nanocarriers: correlation between in vitro occlusion factor and in vivo skin hydrating effect. Pharmaceutics 2017;9:58.

31. ICH. Harmonised tripartite guideline stability testing of new drug substances and products Q1A (R2). 2003.

32. Pople PV, Singh KK. Targeting tacrolimus to deeper layers of skin with improved safety for treatment of atopic dermatitis. Int J Pharm 2010;398(1-2):165-178.

33. Pople PV, Singh KK. Development and evaluation of colloidal modified nanolipid carrier: Application to topical delivery of tacrolimus. Eur J Pharm Biopharm 2011;79:82-94.

34. OECD. OECD guideline for testing of chemicals 404. 2002.

35. Epstein F, Clark R. Cutaneous wound healing. New Eng J Med 1999;341:738-746.

36. Gornall A, Bardawill CJ, David MM. Determination of serum proteins by means of the biuret reaction. J Biolog chem 1949;177:751-766.

37. Ohkawa H, Ohishi N, Yagi K. Assay for lipid peroxides in animal tissues by thiobarbituric acid reaction. Anal biochem 1979;95:351-8.

38. Ellan GL. Tissue sulfhydryl groups. Arch Biochem Biophys 1959;82:70-7.

39. Wadsater M, Barauskas J, Nylander T et al. Formation of Highly Structured Cubic Micellar Lipid Nanoparticles of Soy Phosphatidylcholine and Glycerol Dioleate and Their Degradation by Triacylglycerol Lipase. ACS Appl Mater Interfaces 2014;6:70637069.

40. Priyanka K, Sathali AAH. Preparation and Evaluation of Montelukast Sodium Loaded Solid Lipid Nanoparticles. J of Young Pharmacists: JYP 2012;4(3):129-137.

41. Oliveira M, Nunes D, Toma AR, et al. In vivo topical anti-inflammatory and wound healing 
activities of the fixed oil of Caryocar coriaceum seeds. J Ethnopharmacol 2010;129:214-9.

42. Araújo RR, Teixeira CCC, Freitas LAP. The Preparation of Ternary Solid Dispersions of an Herbal Drug via Spray Drying of Liquid Feed. Drying technol 2010; 28:3, 412-421.

43. Chaudhary S, Garg T, Murthy RS, et al. Recent approaches of lipid-based delivery system for lymphatic targeting via oral route. J Drug Target 2014;1-12.

44. Abdulaziz AA, Ibrahim IA, Mohd MAAK et al. Effect of cryoprotection on particle size stability and preservation of chitosan nanoparticles with and without hyaluronate or alginate coating. Saudi Pharm J 2017;25(6):861-867.

45. Witayaudom $P$ and Klinkesorn U. Effect of surfactant concentration and solidification temperature on the characteristics and stability of nanostructured lipid carrier (NLC) prepared from rambutan (Nephelium lappaceum L.) kernel fat. J Colloid Interface Sci 2017;505:1082-1092.

46. Xiao Y, Chen X, Yang L. Preparation and Oral Bioavailability Study of Curcuminoid Loaded Microemulsion. J Agric Food Chem 2013;61(15):3654-3660.

47. Kumbhar BK, Patil SR, Sawant SM. Synthesis and characterization of magnetorheological (MR) fluids for MR brake application. Eng Sci Technol Int J 2015;18(3):432438.

48. Ferraris CF. Measurement of the Rheological Properties of High Performance Concrete: State of the Art Report. J Res Natl Inst Stand Technol 1999;104:461-478 .

49. Singla AK, Garg A, Aggarwal D, et al. Spreading of semisolid formulations. Pharm. Technol 2002; 84-105.

50. Kushwaha AK, Vuddanda PR, Karunanidhi P, et al. Development and Evaluation of Solid Lipid Nanoparticles of Raloxifene Hydrochloride for Enhanced Bioavailability. BioMed Res Int 2013;2013:584549. 
51. Chen Y, Wu Q, Zhang Z, et al. Preparation of curcumin loaded liposomes and evaluation of their skin permeation and pharmacodynamics. Molecules 2012;17:5972-82.

52. Ban C, Lim S, Chang PS, et al. Enhancing the stability of lipid nanoparticle systems by sonication during the cooling step and controlling the liquid oil content. J Agric Food Chem 2014;62(47):11557-11567.

53. Freitas $\mathrm{C}$ and Müller RH. Correlation between long-term stability of solid lipid nanoparticles (SLN ${ }^{\mathrm{TM}}$ ) and crystallinity of the lipid phase. Eur J Pharm Biopharm 1999;47.2:125-132.

54. Jagetia GC, Rajanikant GK. Acceleration of wound repair by curcumin in the excision wound of mice exposed to different doses of fractionated $\gamma$ radiation. Int Wound J 2012;9:76-92.

55. Dreher R, Walde R, Walther E. Interaction of a lecithin microemulsion gel with human stratum corneum and its effects on transdermal transport. J control release 1997;45:131140.

56. Schubert MA. Characterization of surface modified solid lipid nanoparticles (SLN) Influence of lecithin and non-ionic emulsifier. Eur J Pharm Biopharm 2005;61:77-86.

57. Abdulmohsen A, Al-Saleh AA, Al-Mohizea AM et al. Formulation and characterization of novel soft nanovesicles for enhanced transdermal delivery of eprosartan mesylate. Saudi Pharm J 2017; 1 -7.

58. D'souza AA, Shegokar R. Polyethylene glycol (PEG): a versatile polymer for pharmaceutical applications. Expert Opin Drug Deliv 2016;13(9):1257-1275.

59. Hamishehkar H, Same S, Adibkia K, et al. A comparative histological study on the skin occlusion performance of a cream made of solid lipid nanoparticles and Vaseline. Res Pharm Sci 2015;10(5):378-387. 
60. Sparr E, Millecamps D, Isoir M, et al. Controlling the hydration of the skin though the application of occluding barrier creams. J Royal Soc Interface 2013;10(80):20120788.

61. Dash S, Murthy PN, Nath L. Kinetic modelling on drug release from controlled drug delivery systems. Acta Pol Pharm 2010;67:217-223.

62. Das K. Wound healing potential of aqueous crude extract of Stevia rebaudiana in mice. Rev Bras Farmacogn 2013;149:191-4.

63. Rao AB, Prasad E, Deepthi SS et al. Wound healing: a new perspective on glucosylated tetrahydrocurcumin. Drug Des Devel Ther 2015:9:3579-3588.

64. Shukitt-Hale B, Erat SA, Joseph JA. Spatial learning and memory deficits induced by dopamine administration with decreased glutathione. Free Radic Biol Med 1998;24:11491158.

65. Kakkar V, Kaur IP. Evaluating potential of curcumin loaded solid lipid nanoparticles in aluminium induced behavioural, biochemical and histopathological alterations in mice brain. Food Chem Toxicol 2011;49(11):2906-2913,

66. Kadoma Y, Fujisawa S. Comparative radical-scavenging activity of curcumin and tetrahydrocurcumin with thiols as measured by the induction period method. In Vivo 2007;21:979-982.

67. Park S, Lee LR, Seo JH, et al. Curcumin and tetrahydrocurcumin both prevent osteoarthritis symptoms and decrease the expressions of pro-inflammatory cytokines in estrogendeficient rats. Genes Nutr 2016;11:2.

68. Carr WW. Topical Calcineurin Inhibitors for Atopic Dermatitis: Review and Treatment Recommendations. Paediatr Drugs 2013;15(4):303-310. 


\section{FIGURES}

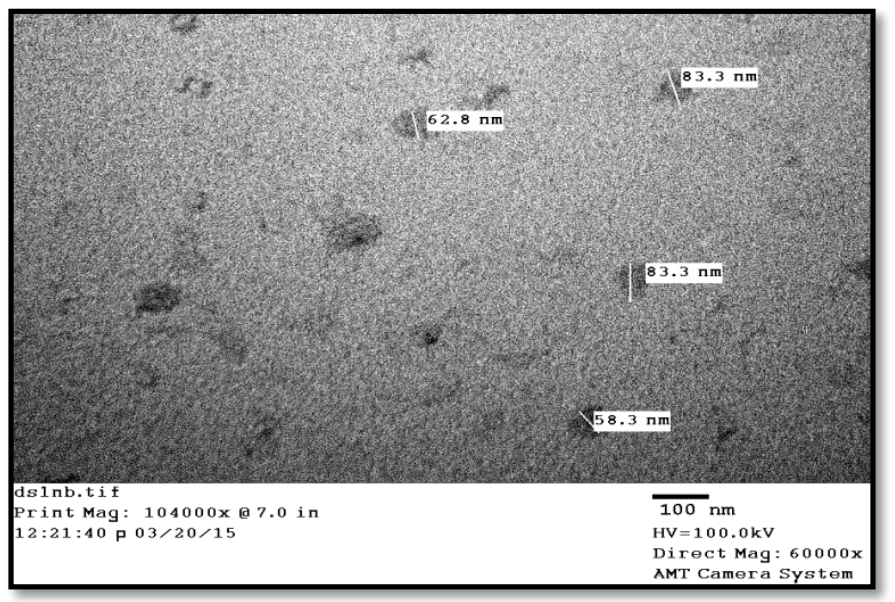

Figure 1 Transmission electron microscopy of THC-SLNs.
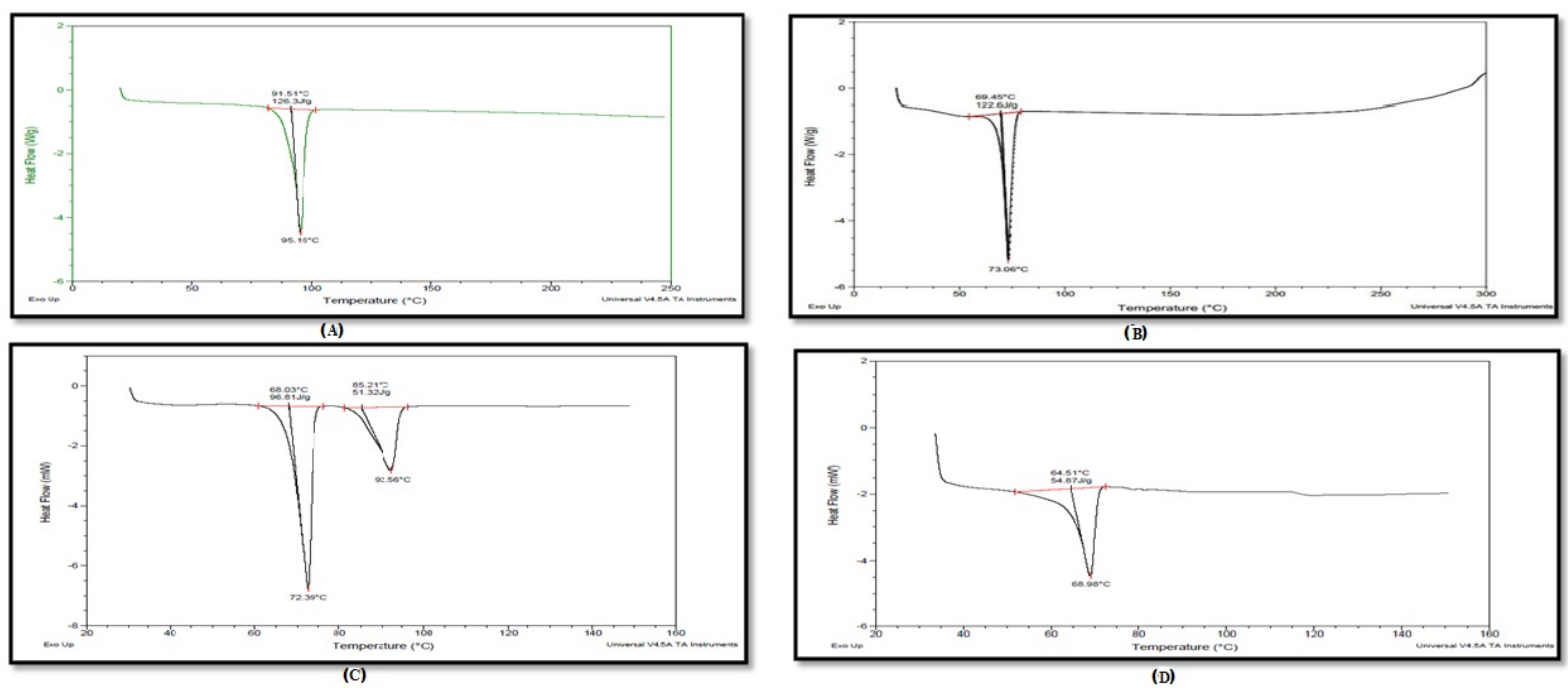

Figure 2. DSC thermogram of (A) THC (B) Compritol ${ }^{\circledR} 888$ ATO (C) Physical mixture of THC and Compritol ${ }^{\circledR} 888$ ATO (D) THC-SLNs. 


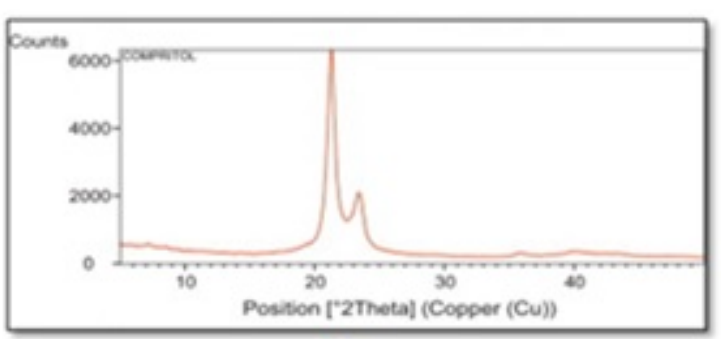

(A)

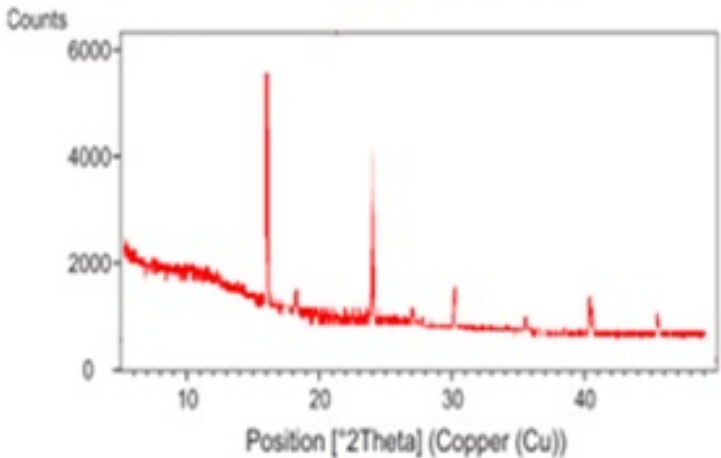

(B)

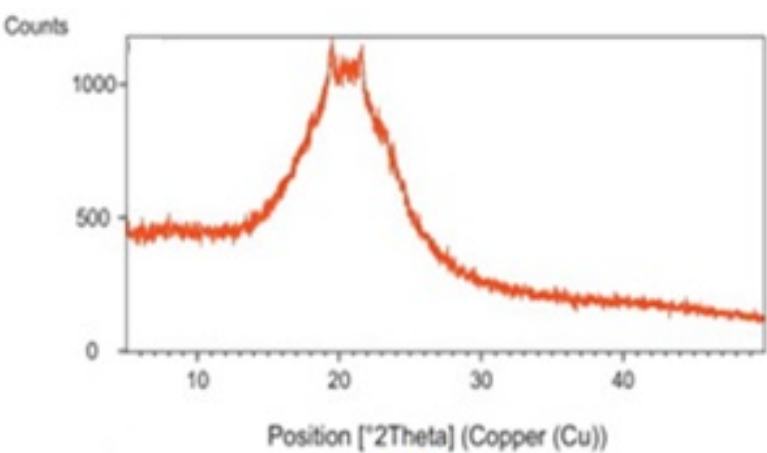

(C)

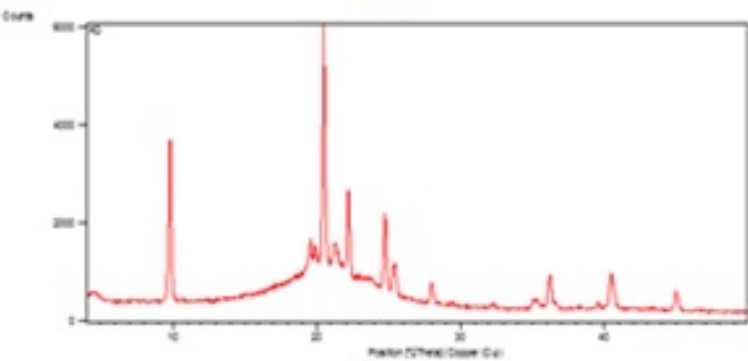

(D)

Figure 3. XRD pattern of (A) Compritol ${ }^{\circledR} 888$ ATO (B) Pure THC (C) Blank SLNs (D)THCSLNs .

(A)

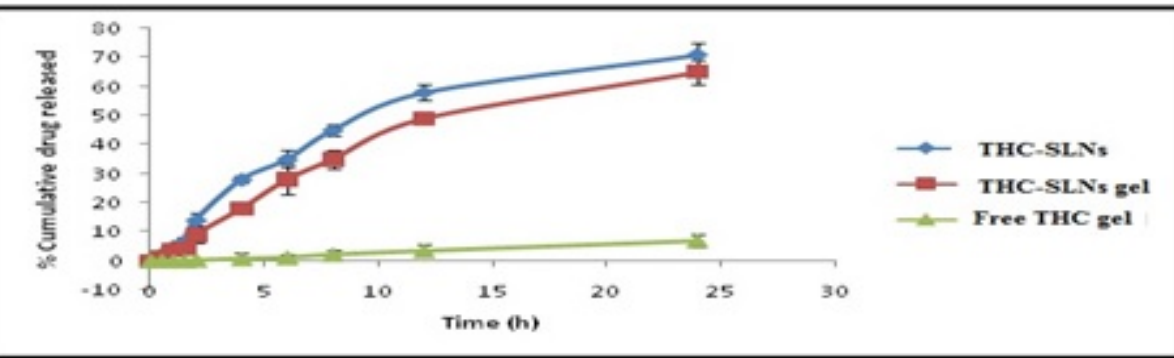

(B)

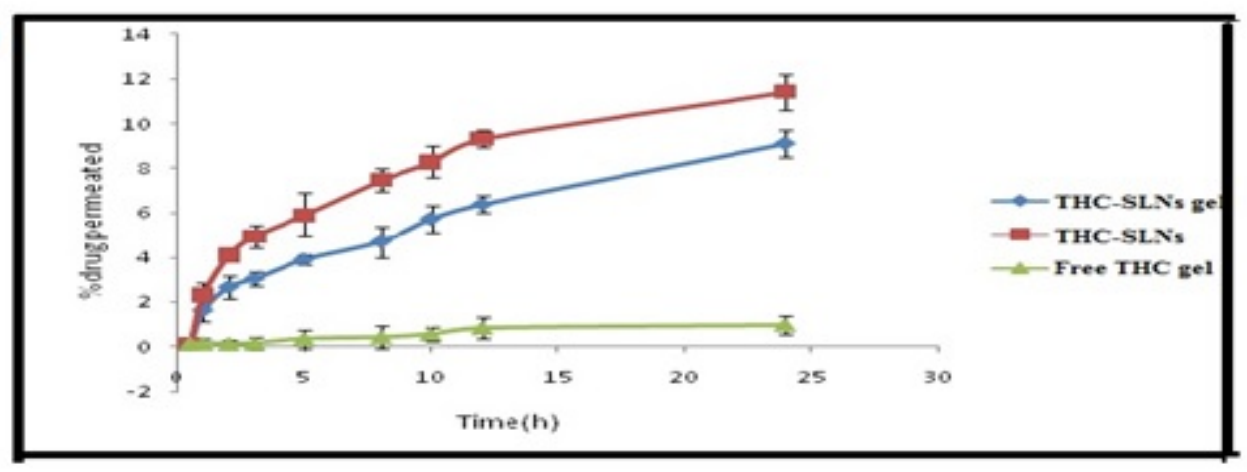

Figure 4. (A) Percentage cumulative amount released versus time (B) Percentage drug permeated versus time. 

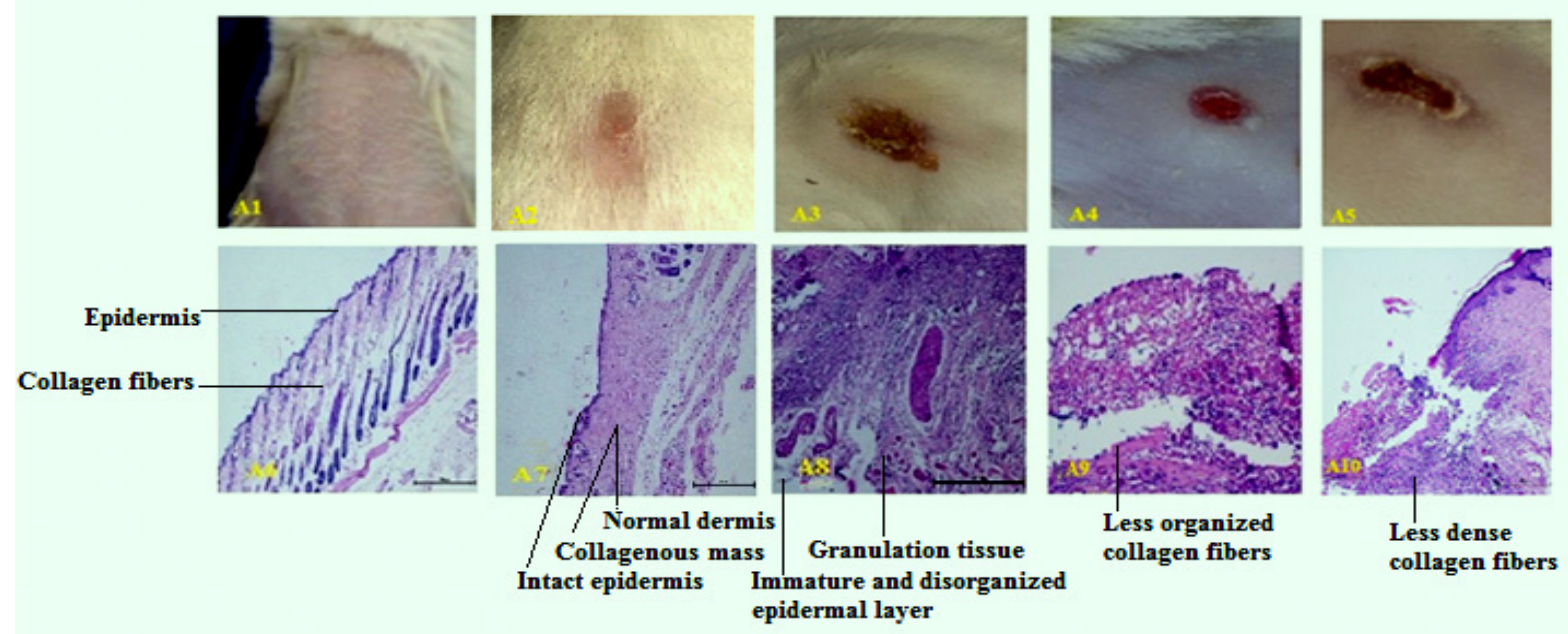

Figure 5. Representative images of the excision wound mice model and histopathological observations, A1 and A6 shows normal skin, A2 and A7 shows THC-SLNs gel, A3 and A8 shows positive control, A4 and A9 shows free THC gel, A5 and A10 shows Blank SLNs respectively.
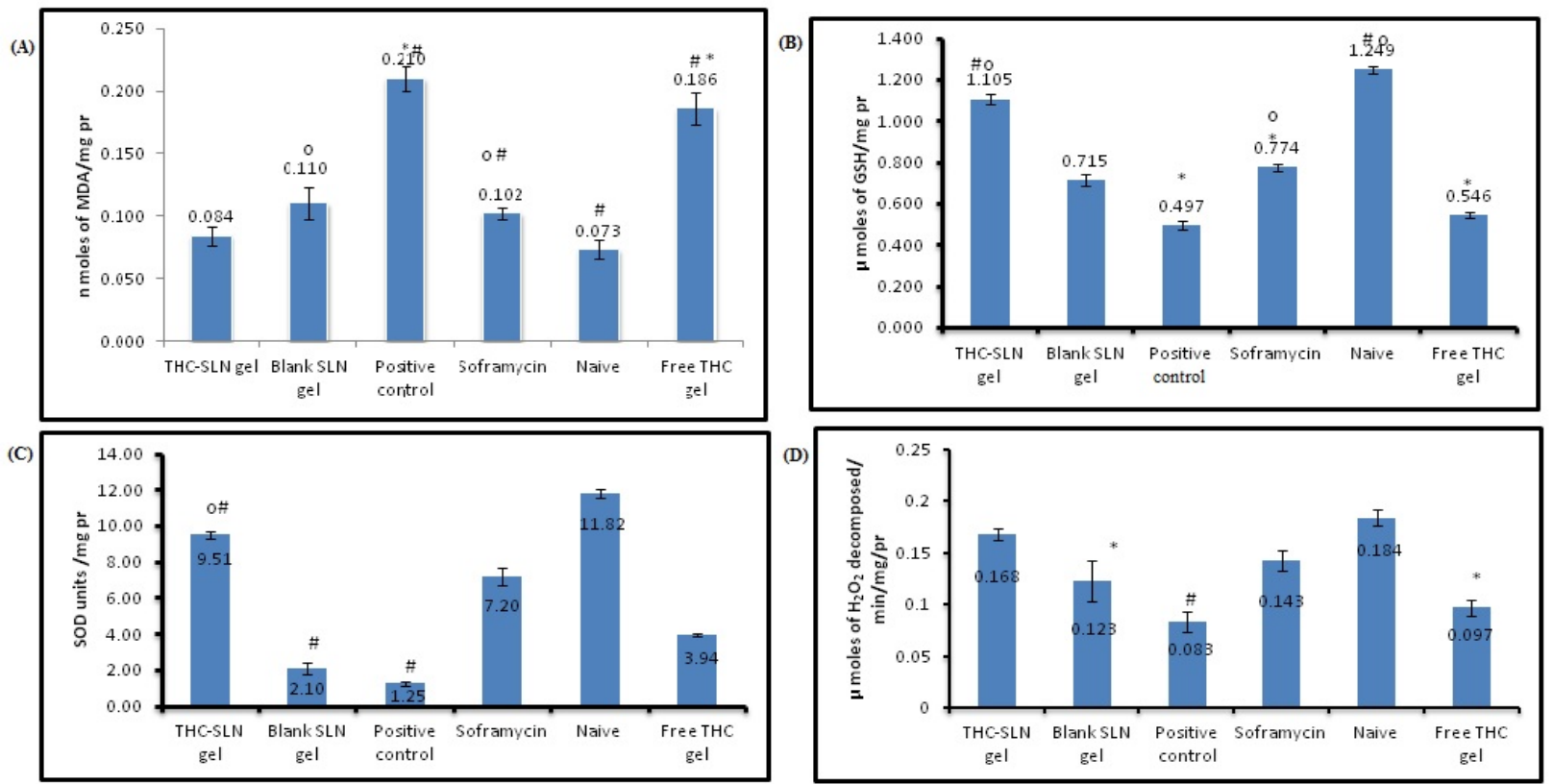

Figure 6. Effect of THC-SLNs gel $(0.2 \%$ w/w), Blank SLNs gel, Positive control, Free THC gel, Naïve on (A) Lipid peroxidation (B) Reduced glutathione levels (C) SOD levels (D) Catalase levels in the skin of mice (excision wound).

*Values are expressed as mean \pm SEM (one way ANOVA followed by Tukey test): ${ }^{*} \mathrm{p}<0.05$ as compared to naïve group; ${ }^{\#} \mathrm{p}<0.05$ as compared to positive group; ${ }^{\circ} \mathrm{p}<0.05$ as compared to Free THC gel group. 


\section{TABLES}

Table 1. Grouping of animals in excision wound mice model.

\begin{tabular}{lll}
\hline S.no. & Group & Treatment $(\mathrm{n}=6)$ \\
\hline 1 & Test & THC-SLNs gel \\
& & $(0.2 \% \mathrm{w} / \mathrm{w})$ \\
2. & Positive Control & No treatment \\
3. & Free THC gel & Free THC gel \\
& & $(0.2 \% \mathrm{w} / \mathrm{w})$ \\
4. & Naive Control & Untreated normal skin \\
5. & Blank gel & Blank SLNs gel \\
\hline
\end{tabular}

Table 2. Occlusion factor measured after 24 and 48 hours for THC-SLN gel, Tacroz ${ }^{\circledR}$ Forte, blank SLNs gel and blank gel without SLNs.

\begin{tabular}{lccccc}
\hline S.no. & Time (h) & \multicolumn{3}{c}{ Occlusion Factor (F) } \\
& & THC-SLNs gel & Tacroz® Forte & Blank SLNs gel & $\begin{array}{l}\text { Blank } \\
\text { without SLNs }\end{array}$ \\
\hline & & & & & \\
1 & 24 & $76.67 \pm 1.02$ & $88.83 \pm 2.32$ & $75.62 \pm 2.45$ & $18.68 \pm 1.30$ \\
2 & 48 & $82.88 \pm 1.08$ & $1.64 \pm 3.27$ & $81.89 \pm 2.15$ & $23.16 \pm 1.10$ \\
\hline
\end{tabular}


Table 3A. Stability studies of THC-SLNs.

\begin{tabular}{|c|c|c|c|c|c|c|}
\hline \multirow{2}{*}{$\begin{array}{l}\text { Time } \\
\text { (months }\end{array}$} & \multicolumn{6}{|c|}{ THC-SLNs } \\
\hline & \multicolumn{3}{|c|}{$4{ }^{\circ} \mathrm{C}$} & \multicolumn{3}{|c|}{$40^{\circ} \mathrm{C}$} \\
\hline & Particle & Total drug & Entrapment & Particle & Total drug & Entrapment \\
\hline & size & content $(\%)$ & efficiency (\%) & size & content $(\%)$ & efficiency (\%) \\
\hline & $(\mathrm{nm})$ & & & $(\mathrm{nm})$ & & \\
\hline 0 & 119.9 & $94.213 \pm 0.058$ & $69.450 \pm 0.135$ & 119.9 & $94.213 \pm 0.058$ & $69.450 \pm 0.135$ \\
\hline 1 & 131.1 & $94.187 \pm 0.104$ & $69.014 \pm 0.047$ & 152.3 & $93.980 \pm 0.151$ & $68.657 \pm 0.111$ \\
\hline 2 & 144.4 & $93.676 \pm 0.120$ & $69.125 \pm 0.124$ & 173.3 & $93.649 \pm 0.183$ & $68.584 \pm 0.027$ \\
\hline
\end{tabular}

Table 3B. Stability studies of THC-SLNs gel.

Time THC-SLNs gel

(months)

\begin{tabular}{|c|c|c|c|c|}
\hline & \multicolumn{2}{|c|}{$25^{\circ} \mathrm{C}$} & \multicolumn{2}{|c|}{$40^{\circ} \mathrm{C}$} \\
\hline & Total drug & Entrapment & Total drug & Entrapment \\
\hline & content $(\%)$ & efficiency $(\%)$ & content $(\%)$ & efficiency $(\%)$ \\
\hline 0 & $99.58 \pm 0.120$ & $68.95 \pm 0.128$ & $99.58 \pm 0.500$ & $68.95 \pm 0.145$ \\
\hline 2 & $98.13 \pm 0.186$ & $67.65 \pm 1.03$ & $98.00 \pm 1.21$ & $66.91 \pm 0.231$ \\
\hline
\end{tabular}

